\title{
Happy Cultures? A Multilevel Model of Well-Being with Individual and Contextual Human Values
}

\author{
Fernando Bruna ${ }^{1}$ (D)
}

Accepted: 30 November 2021 / Published online: 30 December 2021

(c) The Author(s) 2021, corrected publication 2022

\begin{abstract}
Despite the abundant literature in Happiness Science, no paper to date has studied the joint effects of human values on subjective well-being at individual and contextual level. Using European Social Survey data for life satisfaction and Salomon H. Schwartz's scale for human values with four and ten dimensions, this paper presents novel evidence on the direct effects of individual, regional, and national human values, utilizing two different ways of building cultural indicators of human values. We show that regional factors explain approximately $2 \%$ of the dispersion of individual life satisfaction, whereas national factors explain around $12 \%$. The results on the effects of individual human values support Sortheix and Schwartz's hypothesis, with a significant difference: Individual Conformity has a positive impact on well-being, not the negative sign Sortheix and Schwartz predict for Conservation values. We also find positive direct cultural effects for Benevolence and Conformity and negative effects for Tradition. Additionally, we propose a research agenda for human values and contextual effects on well-being studies.
\end{abstract}

Keywords Life satisfaction $\cdot$ Culture $\cdot$ Benevolence $\cdot$ Tradition $\cdot$ Conformity $\cdot$ Conservation

\section{Introduction}

One contributor to differences among the social sciences is each discipline's approach to individuals in a social context. A number of subdisciplines that converge on the new science of well-being have appeared on the margins of social science disciplines. These subdisciplines include social, cultural, and political psychology; socioeconomics; and cultural sociology; among others. Despite expansion of this new science, major questions remain persistently elusive. What role do individual and cultural factors play in determining wellbeing? Although standard definitions of culture mention shared values, norms, and beliefs or expectations, the topic is challenging even if we reduce the focus to human values: Do specific cultures, or cultural attributes, promote individuals' well-being?

Fernando Bruna

f.bruna@udc.es

1 Universidade da Coruña, Research Group on Competition and Development (C\&D) and ECOBAS,

Department of Economics, School of Economics and Business, Campus de Elviña s/n,

15071 A Coruña, Spain 
To limit the scope of this study, we start from Salomon H. Schwartz's theory of human values (Schwartz, 1992; Sagiv \& Schwartz, 2022), which details ten basic human values. The proper empirical method for modelling the joint effects ${ }^{1}$ of individual and cultural human values on individuals' well-being is to estimate multilevel models. Such models are not a panacea, but they are useful tools for analyzing the direct effects of contextual and individual attributes on human behavior or feelings (Duncan et al., 1998). Surprisingly, no previous paper has used multilevel models to evaluate the joint individual and cultural effects of Schwartz's human values on subjective well-being.

The goal of this paper is to study the direct effects of individual and cultural values on subjective life satisfaction, using Schwartz's scale of human values and multilevel models for European Social Survey (ESS) data. We study these effects using two levels of aggregation of human values and two levels of geographical aggregation in Europe, regions and countries. We also compare our results using two different ways of aggregating human values: the means for individual values in each geographical area and the percentage of people with high scores for each value in that territory.

We are trying to encourage debate on detection of cultural attributes that promote the subjective well-being of the average individual within a territory. As discussed below, investigating the positive effects of some cultural attributes on the average individual is compatible with acknowledging the existence of darker aspects of those cultural attributes. We build on Sortheix and Schwartz's (2017) hypotheses about the effects of individual human values on well-being. Although Morrison and Weckroth (2018) studied the effects of four Schwartz's basic human values on well-being at an ecological level, however, no previous research has analyzed individual-and-cultural-level effects jointly. Indeed, Veenhoven's (2015) survey on social conditions for human happiness ignores cultural human values. Therefore, this paper focusses more on detection of statistical cultural patterns than on modelling social well-being (Keyes, 1998), open societies (Krys et al., 2019), or modernization (Welzel \& Inglehart, 2010). Our inquiry is related to Ye et al.'s (2015) analysis of the effects of Geert Hofstede's (1980) nine cultural dimensions, although their study uses ecological data. Evaluating the individual and aggregate effects of ten human values, we conclude that happy cultures are characterized by three of these values: high levels of Benevolence (help others and care for them) and Conformity (follow rules and behave properly), and low levels of Tradition (respect traditions and customs). We highlight these three cultural values to organize the paper's ideas.

Our main contributions are the following. Firstly, we estimate a joint multilevel model for Schwartz's ten basic human values rather than ten separate models for each human value (Sortheix \& Lönnqvist, 2014; Sortheix \& Schwartz, 2017). Secondly, we add two indicators of aggregate human values to this model to attempt to capture direct cultural effects. Thirdly, we compare cultural effects at regional and national level for the four higher-order value dimensions.

Our main results are as follows. Firstly, comparison of our regional and national effects shows that countries explain about $12 \%$ of variance in life satisfaction, whereas regional heterogeneity only explains an additional $2 \%$. This result on the greater significance of the national level is not surprising, but its quantification is novel and has not been measured

\footnotetext{
${ }^{1}$ For reasons of convenience, we use the word effects to refer to statistically significant results in a multilevel model. As we will discuss in Sects. 2 and 3, well-being studies present numerous endogeneity problems. This paper explores only one specific channel of possible causality.
} 


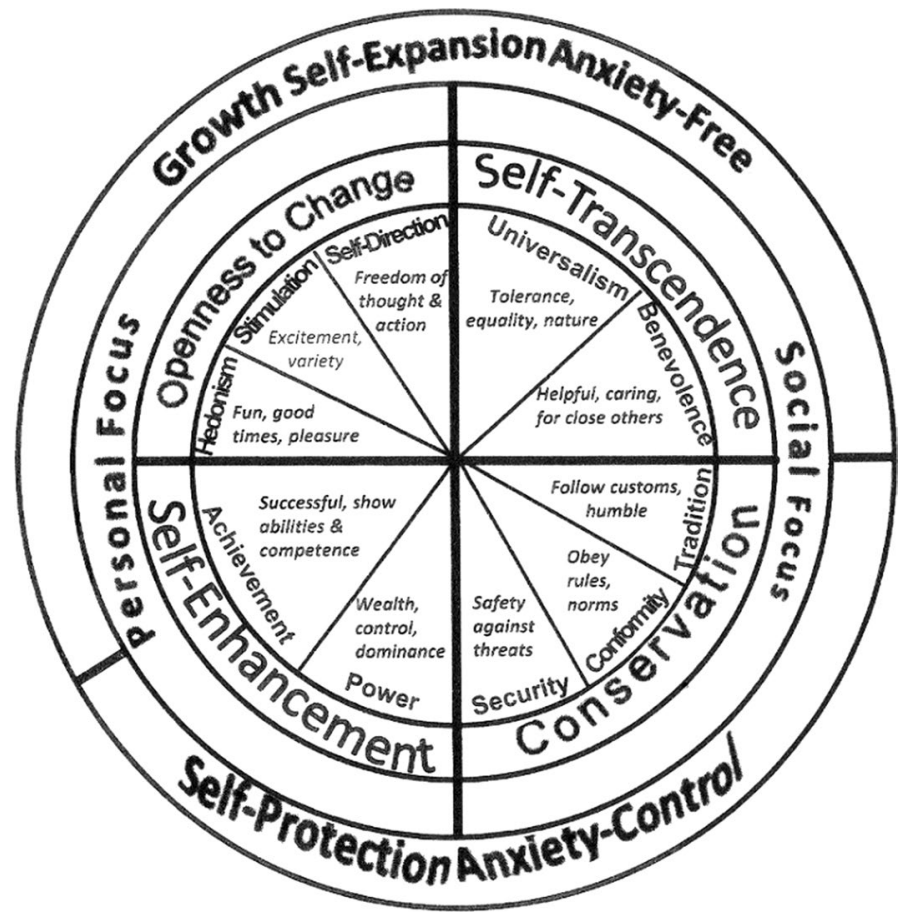

Fig. 1 The circular structure of 10 basic values, four higher order values and two underlying motivational sources. Source: Sortheix and Schwartz (2017)

explicitly in previous multilevel regional papers on well-being (Pittau et al., 2010; Aslam \& Corrado, 2012; Ballas \& Tranmer, 2012; Neira et al., 2018).

Secondly, our findings on the effects of individual human values in individual wellbeing are consistent with Sortheix and Schwartz's (2017) hypotheses, with some significant differences. In the higher-order dimension Conservation, we find a negative effect of Tradition (as expected) but no significant effects of Security. We also find positive effects of Conformity, at both individual and national level. Thirdly, for first time in the literature, we show that individuals' well-being increases in cultures with high emphasis on Benevolence and Conformity and low emphasis on Tradition. The results on Conformity may be the most controversial, and they form part of our proposed research agenda.

The rest of the paper is organized as follows. Section 2 reviews the literature on human values, culture, and well-being, with emphasis on multilevel models. Section 3 describes the methodology and data. Section 4 discusses the results. Finally, Sect. 5 draws conclusions and proposes a research agenda. 
Table 1 Four higher order value dimensions, ten basic values with their motivational goals and the 21 items of the European Social Survey used to measure them

Conservation: Values that emphasize order, self-restriction, and resistance to change

Security - Safety, harmony, and stability of society, of relationships and of self

v05-Important to live in secure and safe surroundings

v14-Important that government is strong and ensures safety

Conformity-Restraint of actions likely to upset others and violate social expectations or norms

v07-Important to do what is told and follow rules

v16-Important to behave properly

Tradition-Respect, commitment and acceptance of the customs and ideas that traditional culture or religion provide

v09-Important to be humble and modest, not draw attention

v20-Important to follow traditions and customs

Openness to Change: Values that emphasize independence of thought, action and feeling and readiness for change

Self-Direction-Independent thought and action-choosing, creating, exploring

v01-Important to think new ideas and being creative

v11-Important to make own decisions and be free

Stimulation-Excitement, novelty, and challenge in life

v06-Important to try new and different things in life

v15-Important to seek adventures and have an exciting life

Hedonism-Pleasure and sensuous gratification for oneself

v10-Important to have a good time

v21-Important to seek fun and things that give pleasure

Self-enhancement: Values that emphasize pursuit of one's interests, relative success, and dominance

Achievement - personal success through demonstrating competence according to social standards

v04-Important to show abilities and be admired

v13-Important to be successful and that people recognize achievements

Power-Social status and prestige, control or dominance over people and resources

v02-Important to be rich, have money and expensive things

v17-Important to get respect from others

Self-transcendence: Values that emphasize concern for the welfare and interests of others

Benevolence-Preservation and enhancement of the welfare of people with whom one is in frequent personal contact

v12-Important to help people and care for others well-being

v18-Important to be loyal to friends and devote to people close

Universalism - Understanding, and protection for the welfare of all and the environment

v03-Important that people are treated equally and have equal opportunities

v08-Important to understand different people

v19-Important to care for nature and environment

Source: Prepared by the authors based on Sortheix and Schwartz (2017) and on ESS documentation 


\section{Theoretical Framework}

\subsection{Schwartz's Scale of Individual Human Values and Subjective Well-Being}

Schwartz (1992) defines values as broad motivational goals that serve as guides to behavior and as criteria for judging people and events. Each value is defined by the goals towards which it is directed, that is, the motivation it expresses. Figure 1 presents the ten basic values and the goals that define them. Values form a circular structure, in which the more compatible any two values are, the closer they are on the circle, and the more they conflict, the farther apart. Table 1 below shows additional details on Schwartz's scale of human values and how they are measured in the ESS. The ten basic values may be grouped into four higher-order values that summarize the opposition between competing values: Conservation versus Openness to Change in the growth dimension and Self-Enhancement versus Self-transcendence in the self-protection dimension. The growth dimension involves relation to self-restriction and order versus novelty and independent thought. The selfprotection dimension captures motivation towards personal interests versus towards others. Moreover, Conservation and Self-transcendence are higher-order values with a social focus, whereas Openness to change and Self-enhancement have a personal focus.

Although the direction of causality is always debatable, ${ }^{2}$ this study focuses on the effects of individual human values on subjective well-being, as surveyed by Schwartz and Sortheix (2018) and Sagiv and Schwartz (2022). Sortheix and Schwartz (2017) argue that growth-oriented values with a personal focus tend to contribute positively to well-being, whereas values oriented to self-protection that have a social focus tend to contribute negatively. Using the four higher-dimension values, therefore, Openness to change values (which combine growth orientation and personal focus) relate positively to subjective wellbeing, whereas Conservation values (which combine self-protection orientation and social focus) relate negatively. As to the effects of Self-enhancement and Self-transcendence on well-being, the opposing implications of growth-protection and social-personal orientation roughly balance each other. As to the four basic values underlying Self-enhancement and Self-transcendence, Sortheix and Schwartz (2017) expect either that one sign will dominate or that no association will occur.

Our main results for individual human values (presented below) are generally consistent with this theory, although we estimate the joint effects of all values, whereas Sortheix and Schwartz (2017) estimate a different model for each of the ten basic values.

\subsection{Culture as Aggregation of Individual Human Values}

Most of the literature cited in this paper comes from psychology and approaches wellbeing from the point of view of individuals' attributes. This approach is also standard in economics. As in other subfields related to socioeconomic development, however, part of the discussion of well-being has been oriented to distinguishing economic and cultural factors (Schyns, 1998). Political science points to institutional factors (Inglehart \& Klingemann, 2000), whereas sociology emphasizes the role of social contexts and socialization (Hitlin \& Piliavin, 2004; Veenhoven, 2015). One line of research on the value-well-being

\footnotetext{
${ }^{2}$ Using panel data, Grosz et al. (2021) conclude that Openness to change values and well-being have a bidirectional influence. See also Sagiv and Schwartz (2022).
} 
relationship focuses on the congruence between individuals' values and those of the environment (Sagiv \& Schwartz, 2000; Morrison \& Weckroth, 2018). This line connects with our cultural approach, although our study seeks to distinguish between the direct effects of individual and cultural human values.

Culture may be defined as the set of values, norms, and beliefs (or expectations) shared to some degree in a social group. Minkov and Hofstede (2014) view culture as values, beliefs, attitudes, and other patterns of thinking and feeling, which provide the software of the mind. Socio-spatial culture refers to the broader societal traits and relations that underlie the prevailing mind-sets and overall way of life in specific places (Huggins \& Thompson, 2019). One preliminary question therefore concerns the interpretation of individual and shared values. A second involves how to operationalize this sharedness empirically.

Schwartz's theory of human values is especially suitable for studying the direct effects of individual and cultural values on well-being because it has adopted a cross-cultural perspective from the beginning (Schwartz, 1992; Goodwin et al., 2020; Sagiv \& Schwartz, 2022). Debate exists, however, about possible differences in the meaning and structure of values at individual versus aggregate level (Fischer \& Poortinga, 2012). A non-isomorphic relationship between the two levels arises if the individual-level value structure is primarily determined by individual-level variables and the country-level value structure primarily by factors that apply at country level. Hofstede states explicitly that his value scale apply only to countries. In a recent seminar, Schwartz declared this an unresolved question, ${ }^{3}$ arguing that nationally representative samples enable us to measure what people are exposed to, that is, what we might call citizens' values rather than cultural values.

We are skeptical about these arguments. Generally speaking, well-being research is trying to estimate the linear effects of endogenous and correlated indicators of human values at individual and aggregate level, treating categorical variables as if they were continuous, ignoring multiple relevant interactions, ignoring many issues of culture (polarization, subcultures, etc.), on a topic with different approaches in different disciplines, under competing theories of human values, and using methodologies with different limitations. Theory-driven empirical inquiries are thus crucial. The search for statistical patterns using alternative methodologies helps, however, to define stylized facts useful to developing theories. Our paper follows the latter direction. For instance, we check the robustness of our results for culture comparing two different indicators of the sharedness of human values, as detailed in Sect. 3.2.

Moreover, Tov and Diener (2009) conclude both that there are pancultural experiences of subjective well-being that can be compared across cultures and that culture-specific patterns make cultures unique in their experience of well-being. This argument supports analysis of heterogeneity in multilevel models of well-being, as noted in the methodological section below. ${ }^{4}$ Most studies of the effects of culture on well-being use ecological data, however (Suh et al., 1998; Ye et al., 2015; among others). Surprisingly, little multilevel research analyzes the individual and aggregate effects of human values on well-being, even though multilevel models are the proper tool for preventing or reducing the possibility of atomistic and ecological fallacies (Snijders \& Bosker, 2012). Below, we summarize some studies involving multilevel research.

\footnotetext{
3 See minute 1:23:00 of the following video, in which Schwartz answers my question about human values and culture: https://www.youtube.com/watch?v=skbG90LJ-G4.

4 See also the following articles by Ed Diener and coauthors: Suh et al. (1998), Krys et al. (2019), and Li et al. (2021).
} 


\subsection{Happy cultures? Three Human Values as Cultural Attributes: Benevolence, Conformity, and Tradition}

This study focuses on cultural direct effects that promote the well-being of individuals living in a specific social environment. We operationalize the concept of a happy cultural attribute as a positive, significant estimate of an aggregate indicator of human values in a multilevel model of individual well-being. This interpretation is compatible with the darker aspects of happy cultures, even for cultures that stress Benevolence. One positive side of cultural Benevolence may be related to enjoyment of social relationships, as the literature on bonding social capital argues (Neira et al., 2018; Bruna \& Rungo, 2020). The details in Table 1 may, however, reveal complex effects. To give a dramatic example, Mafia members from family-oriented cultures will score high on item v18 but low on v12. ${ }^{5}$ Moreover, a culture that values Conformity may encourage well-being because of clear and accepted collective rules. Huxley's 1932 Brave New World exemplifies one potential dark aspect of Conformity. ${ }^{6}$ Further, Andreoni et al. (2021) argue that norms detrimental to social welfare sometimes persist when societies are locked into a conformity trap. Additionally, our models say nothing about how each culture treats minorities or people with deviant values.

We are not proposing a model of positive social health, such as Keyes' (1998) concept of social well-being. Our research question about happy cultures is atheoretical. We ask whether social aggregates of Schwartz's ten basic human values can affect individuals' well-being directly. Our motivation is similar to that of Ye et al. (2015), who studied the effects of nine dimensions of cultural characteristics on subjective well-being, although they based their research on Hofstede's (1980) cultural dimensions and did not use multilevel models. Ye et al. (2015) find that Power distance and Gender egalitarianism play the most important and stable role in determining well-being.

Another more theoretically oriented strand of literature tries to establish empirical links between a particular cultural trait and individual well-being. A first example of this approach is Krys et al.'s (2019) concept of open society, based on four values: trust, tolerance, civic engagement, and nonmaterialism. Using multilevel models, these authors conclude that open societies foster satisfaction and that the positive effect of Hofstede's individualistic cultural attribute disappears when controlling for the effects of open societies. A second example of this approach is Li et al.'s (2021) multilevel model, which reveals that cultural differences on the liberal-conservative continuum moderate the relation between gender inequality and well-being.

A final example of a theory-driven search for cultural effects is Ronald Inglehart's theory of social change. Welzel and Inglehart (2010) and Minkov et al. (2020) use multilevel modelling to analyze a specific causal channel in which modernization affects individualism and emancipative values. Inglehart and Klingemann (2000) show that well-being is

\footnotetext{
5 The possible conflict between v12 and v18 is analogous in Hofstede's human values scale, in which prioritizing family over work is considered a sign of individualism, increasing the indicator of individualism in family-oriented Latin countries, and reducing it in individual-oriented Anglo-Saxon countries. Morrison and Weckroth (2018) note that Benevolence may well strengthen the in-group, but at the expense of the outgroup.

${ }^{6}$ Under an authoritarian or democratic regime, Conformity might make the average individual happier. Indeed, some degree of conformity may be necessary to preserve social equilibrium, since all forms of society have their social problems. This need is one reason why all socialization processes seek to promote adherence to social rules, which is related to the preservation of social structures of power. However, examination of this question is beyond the scope of this paper.
} 
related to economic development, Protestant societies, and democratic institutions. Though our approach is not based on modernization theory, the empirical part of this paper follows Sortheix and Lönnqvist's (2014) focus on the role of contextual socioeconomic development in discussing the robustness of our results when estimation is controlled by a general indicator of socioeconomic development.

\subsection{Regional and National Heterogeneity and Multilevel Studies}

Part of the debate about culture relates to the territory in which culture is evaluated. The interdependence of personality psychology and socio-spatial culture determines the outcomes of urban and regional development (Huggins \& Thompson, 2019), which may affect subjective well-being. Weckroth and Kemppainen (2016), for example, use European regional data to show that Self-direction is a strong predictor of GDP. Morrison and Weckroth (2018) were the first to study the effects of Schwartz's basic human values on wellbeing at an ecological level. They study four human values and compare individuals from Finland's metropolitan region to those from the rest of the country. More generally, however, the degree of cultural heterogeneity across territorial levels is controversial.

Using the ESS and regional indicators of Hofstede's cultural dimensions, Kaasa et al. (2013) conclude that there are striking cultural differences between regions in most countries and that the deeper the subdivision, the larger the differences, which are masked when one indicator is used for the whole country. Conversely, Minkov and Hofstede (2014) also use ESS data to conclude that regions are acceptable but in no way imperative units of analysis. Nations can provide sufficient pictures of cross-cultural variation, at least in terms of values. This last conclusion supports Welzel and Inglehart's (2010) conclusion that cultural differences between nations are considerably greater than those within nations.

Focusing on multilevel studies of well-being, Schyns (2002) analyzes individual and national factors. A few papers have considered regional level: Pittau et al. (2010), Ballas and Tranmer (2012), Aslam and Corrado (2012), and Neira et al. (2018). This literature does not distinguish the proportion of well-being indicators explained by regional versus national factors. The first research question of the empirical part of our paper uses ESS data to detect the most significant level of geographical aggregation for studying cultural effects of well-being.

\section{Empirical Approach}

\subsection{Methodology}

Using the lme4 package for R (Bates et al., 2015), we estimate two- and three-level multilevel (mixed, hierarchical) models in which the one-level data are for individuals $i{ }^{7}$ Some of our models have a second level for regions $(j)$ or countries $(k)$, and the three-level models nest regions $(j k)$ within countries $(k)$. We estimate random intercept models, which capture between-context heterogeneity (Duncan et al., 1998; Neira et al., 2018) to account for aggregate differences in the dependent variable: the territory in which one is located

\footnotetext{
${ }^{7}$ For a general discussion of multilevel modelling, see Snijders and Bosker (2012) or the webpage of the Centre for Multilevel Modelling, University of Bristol.
} 
tends to affect subjective well-being. We thus do not consider random slopes or cross-level interaction, which could model between-individual heterogeneity, in which similar types of people are behaving/feeling differently in different types of places.

Our models are linear. Despite the categorical dependent variable, prior literature summarized by Bruna and Rungo (2020) shows that ordered probit models have results that are qualitatively similar to linear models but harder to interpret. We thus maintain the linear assumption, standard procedure in this literature.

We estimate three types of equations. The empty or null model uses only a global intercept to explain the dependent variable, which is an estimate of the global mean of life satisfaction (see Table 3 below). Random effects enable estimation of region- and countrylevel deviations of life satisfaction from this global mean. ${ }^{8}$ To represent the variance of the residuals at different levels, we use the following notation: $\sigma^{2}$ for individual level, $\sigma_{j}^{2}$ for regional level, and $\sigma_{k}^{2}$ for national level. ${ }^{9}$ Estimating these variances enables us to calculate the proportion of variance of life satisfaction due to (measured or unmeasured) factors common to individuals in the same region or country. This proportion is called the intraclass correlation coefficient (ICC) and is defined as follows in our two-level models:

$$
I C C_{j}=\frac{\sigma_{j}^{2}}{\sigma_{j}^{2}+\sigma^{2}}
$$

for regional level; for national level:

$$
I C C_{k}=\frac{\sigma_{k}^{2}}{\sigma_{k}^{2}+\sigma^{2}}
$$

Our three-level models include random intercepts for regions nested in countries. We present two different $I C C$ s. The first is the national coefficient $I C C_{k}$, as noted above. The second is the joint $I C C$ of regions nested in countries, as follows: ${ }^{10}$

$$
I C C_{j k}=\frac{\sigma_{j}^{2}+\sigma_{k}^{2}}{\sigma_{j}^{2}+\sigma_{k}^{2}+\sigma^{2}}
$$

After the null models, we estimate three-level models including individual-level variables $\left(X_{i j k}\right)$. This method controls for compositional effects: regions or countries could have different propensities to life satisfaction merely because they have different types of individuals. After considering those individual-level variables, we add aggregate variables for regions $\left(X_{j k}\right)$ and countries $\left(X_{k}\right)$. Table 4 below shows the results of these models, considering the four higher-order human values from Schwartz's scale. The final models in the paper, presented in Table 5 below, are two-level models including national random effects and focusing on the ten basic human values in Schwartz's scale at individual and country level.

\footnotetext{
${ }^{8}$ Estimated group effects are weighted averages that combine information from the group itself with information from the mean for all groups. Estimating with random effects is a conservative approach that gives less weight to less reliable data. The random effects are precision-weighted residuals called 'posterior residuals', 'empirical Bayes estimates', or 'shrunken residuals'.

9 The number of national units in the present study (23) should not bias the results (Elff et al., 2021).

${ }^{10}$ Technically, the variance partition coefficients $(V P C)$ are the proportion of response variance at each level of the model hierarchy. Therefore, although $V P C_{k}=I C C_{k}, V P C_{j}=\sigma_{j}^{2} /\left(\sigma_{j}^{2}+\sigma_{k}^{2}+\sigma^{2}\right)$ is not the same as the $I C C_{j k}$ defined in the text.
} 
Although cross-sectional multilevel models cannot distinguish causality between characteristics of individuals and cultures, they provide a major advantage over traditional onelevel studies, which do not differentiate within-context from between-context effects. We therefore use multilevel models for general assessment of possible direct effects of individual and cultural human values on life satisfaction.

This study estimates unweighted multilevel models. "Few things are as confusing to applied researchers as the role of sample weights" (Angrist \& Pischke, 2009, p. 91). The decision whether and how to weight depends on the research goal. Focusing on cultural effects, it is not useful to give more weight to more populated countries. Following the suggestion of Solon et al. (2015) for causal analysis, we compare some of our results to those derived from weighted estimation (Table 6). ${ }^{11}$

\subsection{Data}

We used the eighth round of the ESS to model life satisfaction, an indicator of well-being closely related to cognitive judgments about feeling fulfilled in life or living a good life. Our dependent variable is an indicator resulting from the survey item 'How satisfied are you with life as a whole?' The responses range on a scale from zero (extremely dissatisfied) to ten (extremely satisfied). ${ }^{12}$

The regional classification follows the Eurostat Nomenclature of Territorial Units for Statistics (NUTS), which establishes four aggregation levels, from countries (NUTS 0) to the smallest harmonized territorial units (NUTS 3). ${ }^{13}$ Israel has no regional division, so its data is defined at NUTS level 0). For the other countries, our analysis uses a mix of three NUTS aggregation levels (NUTS 1, 2, and 3), as do Aslam and Corrado (2012) and Neira et al. (2018).

Schwartz's "Computing Scores for the 10 Human values" 14 explains methodological details for computing human values scores in the ESS. Since this survey includes 21 items, ${ }^{15}$ arithmetic means are used to transform the answers to those items into 10 indicators of basic human values, which can be aggregated to 4 higher-dimension human values. This method treats categories from Very much like me to Not like me at all as if they were values for continuous variables, with subjectively comparable significance across the 21 items of the 10 dimensions. Schwartz also recommends calculating each value relative to the sum of the individual's scores for all values. This procedure has pros and cons,

\footnotetext{
11 We used the ESS analysis weights (anweight), which correct for different selection probabilities within each country, as specified by sample design for nonresponse, noncoverage, and sampling error; and considering differences in population size across countries. The United Kingdom, Germany, France, and the Russian Federation constitute $21.9 \%$ of the observations in our sample and have a weight of $59.5 \%$ using anweight.

12 The dependent variable used by Sortheix and Lönnqvist (2014) and Sortheix and Schwartz (2017) is an average of indicators of life satisfaction and happiness. Neira et al. (2018) show some significant differences in the determinants of life satisfaction and happiness.

$13 \mathrm{https} / /$ ec.europa.eu/eurostat/web/nuts/background.

14 See also the following link: http://essedunet.nsd.uib.no/cms/topics/1/4/4.html.

15 For instance, item v07 of the questionnaire on human values reads as follows: 'Now I will briefly describe some people. Please listen to each description and tell me how much each person is or is not like you. Use this card for your answer. She/he believes that people should do what they're told. She/he thinks people should follow rules at all times, even when no-one is watching'. The options are the following: Very much like me; Like me; Somewhat like me; A little like me; Not like me; Not like me at all; Refusal; Don't know; and No answer.
} 
however. The arguments against include the fact that we do not know why some individuals have extreme opinions and others have moderate ones. There is no reason to assume that personal priorities on any topic should be evaluated by centering values on the average score for all values of each individual. Moreover, multilevel models are usually estimated with data centered on the average of a group, which becomes confusing if the individual data are also centered on the average score of each individual for each value. We therefore use the original scores. Table 5 shows a robustness test when using data on relative values.

An additional contribution of this paper is its comparison of alternative methodologies to measure aggregate human values, in both the three-level models (Table 4) and the two-level models (Table 5) below. Aggregate human values are considered in two ways, as (regional or national) means and as shares of people (\%) in the territory who select the options Very much like me or Like me in the questionnaire items about that human value. The indicators are globally centered and standardized by the standard deviation of the observations in each group, 273 regions or 23 countries (Fairbrother et al., 2019). Figure 2 displays the national data for the percentual indicator of three human values selected as relevant to the discussion in Sect. 4.2 below.

To control for other determinants of individual well-being, we consider the following ten possible relevant attributes: Age, Gender, Marital status, Education, Subjective health, Domicile, Political orientations, Religiosity, Trust in others, and Income (see Sect. 4.3 below for details). ${ }^{16}$ Following Sortheix and Lönnqvist (2014), we also control some of our models for a national-level variable, the UNDP's Human Development Index (HDI), as a measure of countries' socioeconomic development.

Table 2 presents the descriptive statistics of the variables used in this paper prior to the transformations of variables explained in the notes on the subsequent tables.

\section{Results}

\subsection{Regional and National Factors Explaining Subjective Well-Being}

Table 3 shows the results for the null models, without explanatory variables. Checking the $I C C_{j}$ of the unconditional model in column (1) of Table 3 , we see that $13 \%$ of the variance in life satisfaction is explained by regional factors. This amount is similar to the $12 \%$ in the $I C C_{k}$ of the model in column (3), which considers only country-level random intercepts. Column (4) presents the results for the three-level models. Comparison of the ICC of column (2) and the difference in ICC s for the equations in column (4) enables us to conclude that regional-level factors help to explain only $2.1 \%$ of the dispersion of life satisfaction when national-level communalities are controlled for, ${ }^{17,}{ }^{18}$ Europeans' well-being is given mainly by factors distributed at the individual level, but a significant $11.8 \%$ of the

\footnotetext{
16 Although some of these controls may be affected by underlying values, the results for the control variables when human values are excluded from the model (not shown) are very similar.

17 We use the expression fixed effects to indicate dummy variables capturing communalities, particularly geographical areas. Differences among countries might stem from the quality of democracy, freedom of the press, institutions, and/or other factors. See, for example, Veenhoven (2015). We do not use these effects in the following tables in the paper. Controlling contextual differences out through use of dummy variables removes contextual variance, losing important information (Bell and Jones 2015).

18 As mentioned in Sect. 3.2, Israel has no regional division, but the ICC s discussed in the text are roughly the same when Israel is excluded from the sample.
} 


\section{Conformity}

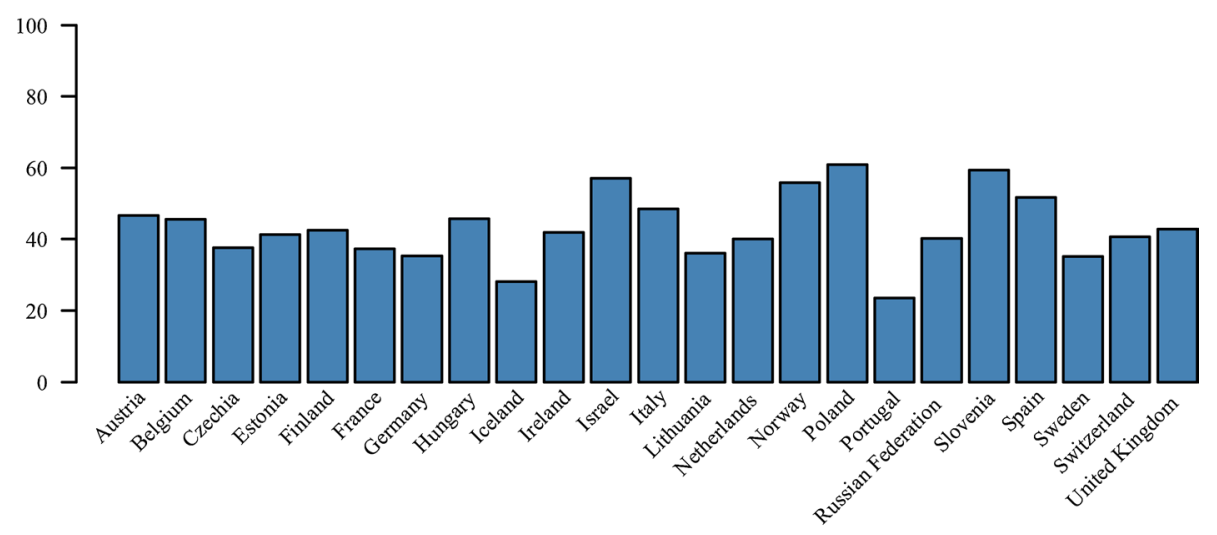

Tradition

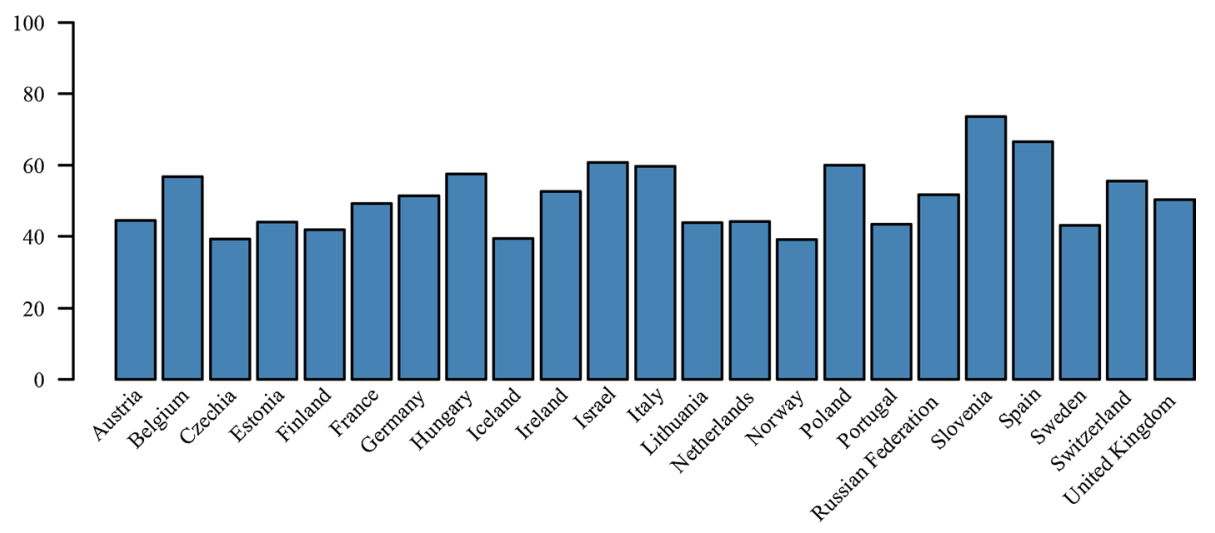

Benevolence

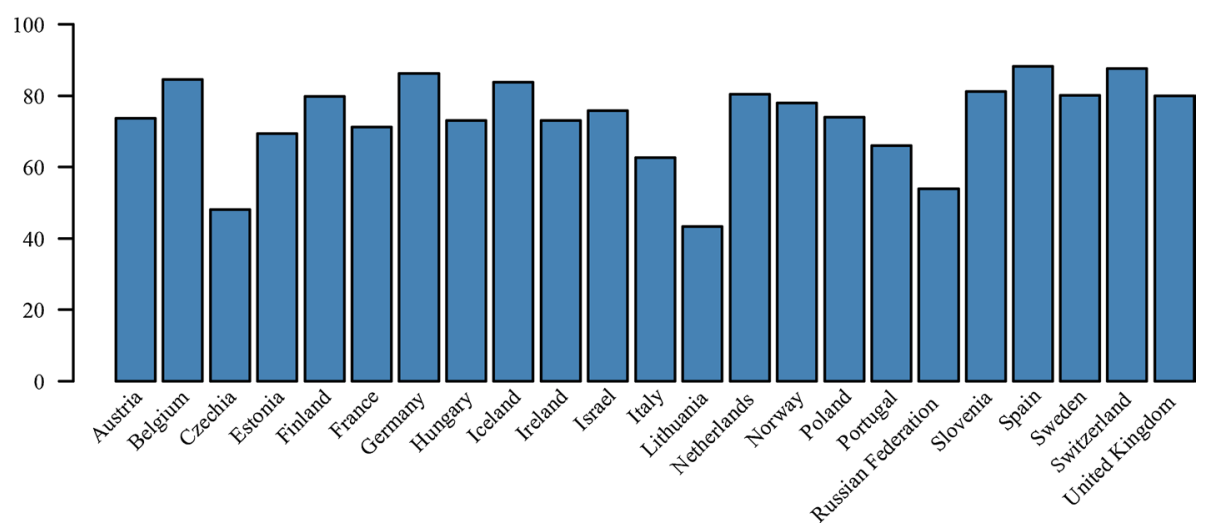

Fig. 2 Share (\%) of respondents in each country with high identification (like or very much like) with sentences about the importance of three selected human values 
Table 2 Descriptive statistics

$\begin{array}{lllll}\text { Mean } & \begin{array}{l}\text { Standard } \\ \text { deviation }\end{array} & \text { Median } & \text { Minimum } & \text { Maximum }\end{array}$

\begin{tabular}{|c|c|c|c|c|c|}
\hline \multicolumn{6}{|c|}{ Individual variables, $X_{i j k}(31,386 \mathrm{obs})}$. \\
\hline Age & 50.03 & 17.94 & 50.00 & 15.00 & 99.00 \\
\hline Gender & 1.51 & 0.50 & 2.00 & 1.00 & 2.00 \\
\hline Marital status & 2.25 & 0.64 & 2.00 & 1.00 & 3.00 \\
\hline Tertiary education & 0.27 & 0.44 & 0.00 & 0.00 & 1.00 \\
\hline Subjective health & 2.19 & 0.55 & 2.00 & 1.00 & 3.00 \\
\hline Living in village-farm & 0.36 & 0.48 & 0.00 & 0.00 & 1.00 \\
\hline Political orientation & 2.04 & 0.69 & 2.00 & 1.00 & 3.00 \\
\hline Religiosity & 1.91 & 0.83 & 2.00 & 1.00 & 3.00 \\
\hline Trust in others & 2.18 & 0.75 & 2.00 & 1.00 & 3.00 \\
\hline Income & 1.95 & 0.75 & 2.00 & 1.00 & 3.00 \\
\hline Conservation & 4.31 & 0.82 & 4.33 & 1.00 & 6.00 \\
\hline Self-transcendence & 4.88 & 0.70 & 5.00 & 1.00 & 6.00 \\
\hline Openness to change & 4.09 & 0.86 & 4.17 & 1.00 & 6.00 \\
\hline Self-enhancement & 3.51 & 1.02 & 3.50 & 1.00 & 6.00 \\
\hline Security & 4.61 & 1.04 & 5.00 & 1.00 & 6.00 \\
\hline Conformity & 4.03 & 1.11 & 4.00 & 1.00 & 6.00 \\
\hline Tradition & 4.28 & 1.01 & 4.50 & 1.00 & 6.00 \\
\hline Benevolence & 4.97 & 0.82 & 5.00 & 1.00 & 6.00 \\
\hline Universalism & 4.79 & 0.78 & 5.00 & 1.00 & 6.00 \\
\hline Self-direction & 4.64 & 0.94 & 5.00 & 1.00 & 6.00 \\
\hline Stimulation & 3.56 & 1.20 & 3.50 & 1.00 & 6.00 \\
\hline Hedonism & 4.06 & 1.14 & 4.00 & 1.00 & 6.00 \\
\hline Achievement & 3.73 & 1.22 & 4.00 & 1.00 & 6.00 \\
\hline Power & 3.28 & 1.08 & 3.50 & 1.00 & 6.00 \\
\hline \multicolumn{6}{|c|}{ Regional variables (means), $X_{j k}(273$ obs.) } \\
\hline Conservation & 4.33 & 0.31 & 4.30 & 3.72 & 5.12 \\
\hline Self-transcendence & 4.85 & 0.29 & 4.92 & 3.56 & 5.44 \\
\hline Openness to change & 4.07 & 0.25 & 4.08 & 2.88 & 4.79 \\
\hline Self-enhancement & 3.50 & 0.46 & 3.43 & 2.46 & 4.63 \\
\hline \multicolumn{6}{|c|}{ Regional variables (\%), $X_{j k}(273$ obs.) } \\
\hline Conservation & 53.04 & 11.11 & 51.45 & 23.15 & 81.67 \\
\hline Self-transcendence & 70.61 & 12.79 & 73.51 & 22.74 & 93.75 \\
\hline Openness to change & 44.64 & 8.62 & 44.73 & 16.51 & 69.40 \\
\hline Self-enhancement & 28.85 & 11.97 & 26.99 & 9.53 & 61.66 \\
\hline \multicolumn{6}{|c|}{ National variables (means), $X_{k}(23$ obs.) } \\
\hline Conservation & 4.31 & 0.25 & 4.27 & 3.86 & 4.73 \\
\hline Self-transcendence & 4.85 & 0.24 & 4.88 & 4.21 & 5.21 \\
\hline Openness to change & 4.09 & 0.21 & 4.09 & 3.68 & 4.43 \\
\hline Self-enhancement & 3.55 & 0.42 & 3.55 & 2.83 & 4.29 \\
\hline Security & 4.62 & 0.31 & 4.60 & 3.90 & 5.03 \\
\hline Conformity & 4.02 & 0.27 & 4.00 & 3.50 & 4.51 \\
\hline Tradition & 4.29 & 0.26 & 4.22 & 3.86 & 4.81 \\
\hline Benevolence & 4.94 & 0.28 & 5.00 & 4.17 & 5.30 \\
\hline
\end{tabular}


Table 2 (continued)

\begin{tabular}{|c|c|c|c|c|c|}
\hline & Mean & $\begin{array}{l}\text { Standard } \\
\text { deviation }\end{array}$ & Median & Minimum & Maximum \\
\hline Universalism & 4.77 & 0.21 & 4.80 & 4.25 & 5.13 \\
\hline Self-direction & 4.62 & 0.21 & 4.64 & 4.10 & 5.01 \\
\hline Stimulation & 3.58 & 0.16 & 3.55 & 3.34 & 3.92 \\
\hline Hedonism & 4.07 & 0.35 & 4.20 & 3.34 & 4.66 \\
\hline Achievement & 3.77 & 0.44 & 3.78 & 3.06 & 4.64 \\
\hline Power & 3.33 & 0.44 & 3.32 & 2.61 & 4.07 \\
\hline \multicolumn{6}{|c|}{ National variables (\%), $X_{k}(23$ obs.) } \\
\hline Conservation & 52.04 & 8.89 & 52.13 & 38.20 & 71.72 \\
\hline Self-transcendence & 70.36 & 10.60 & 71.79 & 45.10 & 85.36 \\
\hline Openness to change & 45.07 & 7.23 & 44.83 & 32.18 & 59.70 \\
\hline Self-enhancement & 29.68 & 11.04 & 29.13 & 14.09 & 51.64 \\
\hline Security & 62.12 & 11.43 & 63.25 & 37.49 & 82.25 \\
\hline Conformity & 43.23 & 9.39 & 41.96 & 23.51 & 60.98 \\
\hline Tradition & 50.78 & 9.31 & 50.32 & 39.08 & 73.50 \\
\hline Benevolence & 73.66 & 12.05 & 75.86 & 43.30 & 88.20 \\
\hline Universalism & 67.06 & 9.50 & 67.71 & 46.89 & 82.53 \\
\hline Self-direction & 61.37 & 8.81 & 61.40 & 43.08 & 76.99 \\
\hline Stimulation & 30.87 & 4.99 & 29.81 & 23.28 & 44.54 \\
\hline Hedonism & 42.96 & 10.81 & 44.12 & 23.60 & 61.51 \\
\hline Achievement & 34.91 & 12.43 & 31.08 & 16.59 & 62.28 \\
\hline Power & 24.45 & 10.62 & 21.12 & 9.84 & 44.09 \\
\hline $\begin{array}{l}\text { Human Development Index, } \\
\boldsymbol{X}_{\boldsymbol{k}}(23 \text { obs.) }\end{array}$ & 0.90 & 0.04 & 0.90 & 0.82 & 0.95 \\
\hline
\end{tabular}

The table shows descriptive statistics of the variables before possible transformations done for the equations in later tables. Further details about the individual control variables are provided in Table 7. The six categories of each of the 21 ESS items detailed in Table 1 have been inverted, so higher figures in the resulting variables indicate more importance given to that topic. Despite being categorical, individual human values are considered as continuous variables, as it is common in this literature. For the estimations in this paper, they are group mean centered (by the regional or national averages, depending on the estimated model) and standardized. Aggregated human values are (regional or national) means, or shares of people in that territory selecting high identification. They have been globally centered and standardized, the same than the national Human Development Index

dispersion of life satisfaction is given by national factors and a marginal additional $2.1 \%$ by regional factors.

To explore this result further, Table 4 shows the estimation of three-level models after controlling for compositional effects that might explain different types of people in different regions or countries (see Sect. 4.3). Column (1) shows that country-level factors explain $8.3 \%$ of the unexplained part (residuals) of life satisfaction after controlling for these individual characteristics. Regional random effects add 1.6-1.7\% additional explanation in all columns of Table 4.

Equations in columns (2) to (6) of Table 4 introduce standardized variables of human values, whose estimates are comparable. Columns (3) and (4) include our two indicators of aggregate human values defined at regional level. The two regional indicators of Self-transcendence seem initially to be statistically significant. However, in columns (5) and (6), 
Table 3 Two-and-three-level multilevel null models for life satisfaction of 31,386 individuals $(i)$ in 273 regions $(j)$ of 23 countries $(k)$

\begin{tabular}{lllll}
\hline & $(1)$ & $(2)$ & $(3)$ & $(4)$ \\
\hline Intercept) & $8.17^{* * *}$ & & $8.21^{* * *}$ & $8.20^{* * *}$ \\
$\begin{array}{l}\text { National fixed effects } \\
\text { Random Effects }\end{array}$ & No & Yes & No & No \\
$\sigma^{2}$ & 3.57 & 3.57 & 3.64 & 3.57 \\
$\sigma_{j}^{2}$ & 0.53 & 0.09 & & 0.09 \\
$\sigma_{k}^{2}$ & & & 0.49 & 0.49 \\
$I C C_{j}$ & 0.128 & 0.021 & & \\
ICC & & & 0.119 & 0.118 \\
ICC & & & & 0.139 \\
Deviance & & & & 129,726 \\
\hline
\end{tabular}

$p$ values, symbolized through stars, are calculated using the Satterthwaite approximation to the degrees of freedom. Equations in columns (1) and (2) include regional random intercepts. Equation in column (3) includes national random intercepts. Equation in column (4) include random intercepts by regions nested in countries. Lower Deviance between comparable models implies better linear fit

this cultural trait becomes significant at national but at not regional level, when nationallevel indicators are included in the model.

Country-level between-group differences thus seem to be much more significant than regional differences in explaining cultural influences of human values on life satisfaction. For simplicity, Table 5 shows an analysis of the effects of the ten basic human values in a two-level model including only national random intercepts.

\subsection{Basic Human Values at Individual and National Level}

Table 4 shows that two dimensions of the four-dimensional scale of individual human values have positive effects on life satisfaction, Self-transcendence and Openness to change. Self-enhancement, in contrast, seems to have negative effects. Conservation is not statistically significant. Our results are consistent with Sortheix and Schwartz's (2017) theory except in this last variable, as explained in Sect. 2.1. Table 5 (columns 1-3) presents more detailed results for the ten-dimensional scale of individual human values. ${ }^{19}$

In Table 5, individual Hedonism is the basic human value with the largest (positive) estimate, explaining why Openness to change shows the highest estimate in Table 4. As predicted by Sortheix and Schwartz (2017), Openness to change has positive significant effects in Table 4, although Stimulation is not significant in Table 5. In Table 4, individual Self-transcendence has a positive sign due the positive role of Benevolence in Table 5, since Universalism is not significant in Table 5. This finding is consistent with Sortheix and Schwartz's (2017) hypothesis. Although the second-largest estimate in Table 5 is for Benevolence, the combined negative significant effect of Achievement and Power makes

\footnotetext{
19 Our model for joint values does not show significant effects for individual Security, Universalism, and Stimulation. Sortheix and Schwartz's (2017) separate models for each value do not show significant results for Universalism and Achievement.
} 
Table 4 Three-level multilevel models of life satisfaction for four dimensions of human values

(1)

(3)

(4)

(5)

(6)

Individual variables, $X_{i j k}$

Conservation

$\begin{array}{rrrr}0.00 & 0.00 & 0.00 & 0.00 \\ 0.09^{* * * *} & 0.09^{\text {*** }} & 0.09^{* * *} & 0.09 \\ 0.15^{* * *} & 0.15^{\text {*** }} & 0.15^{\text {*** }} & 0.15 \\ -0.12^{\text {*** }} & -0.12^{\text {*** }} & -0.12^{\text {*** }} & -0.12 \\ & & & \\ & -0.01 & & 0.02 \\ & 0.13^{*} & & 0.07 \\ & 0.07 & & 0.06 \\ & -0.07 & & -0.04\end{array}$

Self-transcendence

Openness to change

Self-enhancement

Regional variables (means), $X_{j k}$

Conservation

Self-transcendence

Openness to change

Self-enhancement

Regional variables (\%), $X_{j k}$

Conservation

$\begin{array}{rr}-0.04 & \\ 0.18^{* *} & \\ 0.04 & \\ -0.03 & \\ & -0.29 \\ & 0.49^{*} \\ & -0.17 \\ & 0.26\end{array}$

Self-transcendence

Openness to change

Self-enhancement

National variables (means), $X_{k}$

Conservation

Self-transcendence

Openness to change

Self-enhancement

National variables (\%), $X_{k}$

Conservation

Self-transcendence

Openness to change

Self-enhancement

Random effects

\begin{tabular}{lrrrrrr}
$\sigma^{2}$ & 2.99 & 2.97 & 2.97 & 2.97 & 2.97 & 2.97 \\
$\sigma_{j}^{2}$ & 0.05 & 0.05 & 0.05 & 0.05 & 0.05 & 0.05 \\
$\sigma_{k}^{2}$ & 0.27 & 0.28 & 0.17 & 0.16 & 0.13 & 0.11 \\
$I C C_{k}$ & 0.083 & 0.084 & 0.054 & 0.051 & 0.040 & 0.035 \\
$I C C_{j k}$ & 0.099 & 0.101 & 0.070 & 0.068 & 0.056 & 0.052 \\
Deviance & 123,817 & 123,527 & 123,506 & 123,507 & 123,494 & 123,493 \\
\hline
\end{tabular}

$* p<0.05 * * p<0.01 * * * p<0.001$

See details in Tables 2 and 7 for the individuals' control variables, omitted here. Individual human values are centered on the regional means and standardized. All the models include random intercepts by regions nested in countries

Self-enhancement the second-largest higher-order estimate in Table 4, even though Sortheix and Schwartz's (2017) model yields an ambiguous expectation for Achievement. We will discuss the results of individual Conservation values below.

Columns (2) and (3) of Table 5 show the results when our globally standardized country-level indicators of human values are added to the equation in column (1): national means of the individual human values and national percentages of citizens selecting high 
Table 5 Two-level multilevel models of life satisfaction for ten dimensions of human values

\begin{tabular}{|c|c|c|c|c|c|c|c|c|}
\hline & (1) & (2) & (3) & (4) & $(5)$ & (6) & (7) & (8) \\
\hline \multicolumn{9}{|c|}{ Individual variables, $X_{i k}$} \\
\hline Security & -0.02 & -0.02 & -0.02 & & & & & \\
\hline Conformity & $0.04^{* * * *}$ & $0.04^{* * *}$ & $0.04^{* * * *}$ & $0.06^{* * *}$ & $0.04^{* *}$ & $0.04^{* *}$ & $0.04^{* *}$ & $0.04^{* *}$ \\
\hline Tradition & $-0.04^{* * * *}$ & $-0.04^{* * *}$ & $-0.04^{* * *}$ & $-0.03^{* *}$ & $-0.05^{* * *}$ & $-0.05^{* * *}$ & $-0.05^{* * *}$ & $-0.05^{* * *}$ \\
\hline Benevolence & $0.14^{* * *}$ & $0.14^{* * *}$ & $0.14^{* * *}$ & $0.12^{* * *}$ & $0.13^{\text {**** }}$ & $0.13^{* * * *}$ & $0.13^{* * *}$ & $0.13^{* * *}$ \\
\hline Universalism & -0.01 & -0.01 & -0.01 & & & & & \\
\hline Self-direction & $0.04^{* *}$ & $0.04^{* *}$ & $0.04^{* *}$ & $0.04^{* *}$ & $0.03^{\text {*** }}$ & $0.03^{* *}$ & $0.03^{* *}$ & $0.03^{\text {** }}$ \\
\hline Stimulation & -0.01 & -0.01 & -0.01 & & & & & \\
\hline Hedonism & $0.18^{* * *}$ & $0.18^{* * *}$ & $0.18^{* * *}$ & $0.17^{* * *}$ & $0.17^{\text {**** }}$ & $0.17^{* * *}$ & $0.17^{* * *}$ & $0.17^{\text {**** }}$ \\
\hline Achievement & $-0.07^{* * *}$ & $-0.07^{* * *}$ & $-0.07^{* * *}$ & $-0.03^{*}$ & $-0.08^{* * *}$ & $-0.08^{* * *}$ & $-0.08^{* * *}$ & $-0.08^{* * *}$ \\
\hline Power & $-0.08^{* * * *}$ & $-0.08^{* * *}$ & $-0.08^{* * *}$ & $-0.06^{* * *}$ & $-0.08^{* * *}$ & $-0.08^{* * *}$ & $-0.08^{* * *}$ & $-0.08^{* * *}$ \\
\hline \multicolumn{9}{|c|}{ National variables (means), $X_{k}$} \\
\hline Security & & -0.01 & & & & & & \\
\hline Conformity & & 0.12 & & 0.10 & $0.21^{\text {**** }}$ & & $0.15^{* *}$ & \\
\hline Tradition & & $-0.52^{* *}$ & & -0.16 & $-0.27^{* * * *}$ & & -0.11 & \\
\hline Benevolence & & 0.24 & & $0.35^{* * *}$ & $0.46^{* * *}$ & & $0.29^{* * *}$ & \\
\hline Universalism & & 0.30 & & & & & & \\
\hline Self-direction & & 0.18 & & & & & & \\
\hline Stimulation & & -0.03 & & & & & & \\
\hline Hedonism & & -0.14 & & & & & & \\
\hline Achievement & & 0.20 & & & & & & \\
\hline Power & & 0.12 & & & & & & \\
\hline \multicolumn{9}{|c|}{ National variables (\%), $X_{k}$} \\
\hline Security & & & -0.06 & & & & & \\
\hline Conformity & & & 0.09 & & & $0.19^{*}$ & & $0.13^{*}$ \\
\hline Tradition & & & $-0.41^{*}$ & & & $-0.27^{* * *}$ & & -0.12 \\
\hline Benevolence & & & 0.43 & & & $0.46^{* * * *}$ & & $0.27^{* *}$ \\
\hline Universalism & & & 0.19 & & & & & \\
\hline Self-direction & & & 0.07 & & & & & \\
\hline Stimulation & & & -0.00 & & & & & \\
\hline Hedonism & & & -0.15 & & & & & \\
\hline Achievement & & & 0.20 & & & & & \\
\hline Power & & & 0.06 & & & & & \\
\hline$H D I, X_{k}$ & & & & & & & $0.26^{* * * *}$ & $0.26^{* *}$ \\
\hline \multicolumn{9}{|c|}{ Random Effects } \\
\hline$\sigma^{2}$ & 2.99 & 2.99 & 2.99 & 3.00 & 2.99 & 2.99 & 2.99 & 2.99 \\
\hline$\sigma_{k}^{2}$ & 0.28 & 0.05 & 0.09 & 0.13 & 0.06 & 0.07 & 0.03 & 0.04 \\
\hline$I C C_{k}$ & 0.085 & 0.017 & 0.028 & 0.041 & 0.019 & 0.022 & 0.010 & 0.014 \\
\hline Deviance & 123,534 & 123,487 & 123,497 & 123,601 & 123,500 & 123,504 & 123,484 & 123,492 \\
\hline
\end{tabular}

$* p<0.05 * * p<0.01 * * * p<0.001$.

See details in the other tables and in the main text. Figure 2 shows the data of the cultural variables included in column (6) before being globally centered and standardized. 
identification with those values. Only the negative effects of Tradition become significant. Country-level variables tend, however, to correlate much more highly than individual-level variables. ${ }^{20}$ In columns (5) and (6) of Table 5, we thus make a preliminary selection of three cultural human values. This selection shows that the main positive cultural effect comes from being in a country with high Benevolence, a finding consistent with the results for national Self-transcendence in Table 4.

At both individual and national level, two Conservation values seem to have opposite signs, Conformity positive and Tradition negative, while Security is not statistically significant. The positive effect of individual Conformity contradicts Sortheix and Schwartz's (2017) theoretical prediction. In examining the details summarized in Table 1 for these two values, one possible explanation could be that Conformity tends to reward fit to any socially accepted norm, whereas Tradition rewards adaptation to specific norms related to customs, religion, or family. Our results may, however, be driven by attributes of a set of countries in our sample. Detailed analysis is beyond the scope of this paper.

As mentioned in Sect. 3.2, Table 5 also includes a robustness analysis of the measurement of human values. The estimated model in columns (4) and (5) is the same, but column (4) shows the results when human values are centered on the mean of all human values for each individual before subsequent transformation of variables for our multilevel models. National Tradition becomes non-significant in column (4), but its Satterthwaite's p-value is low (0.058) (not shown in the table). The main difference thus involves national Conformity, not statistically significant in column (4).

Additionally, the last two columns of Table 5 check the robustness of our results on inclusion of the HDI. National Tradition is no longer statistically significant at 5\% level, though its p-value is still relatively low, 0.09 in column (7) and 0.11 in column (8) (not shown in Table 5). As discussed in Sect. 2.3, this result is consistent with modernization theory and does not contradict the conclusion that cultures with high presence of traditional values constrain subjective well-being. Moreover, the standardized estimates of national Benevolence are about $40 \%$ lower when the HDI is included in the model. This result is also consistent with modernization theory and confirms an independent role of the cultural channel in explaining individual well-being (Inglehart \& Baker, 2000). Our preferred models are thus those in columns (5) and (6), which stress the direct link between culture and individual subjective well-being.

Following the discussion at the end of Sect. 3.1, Table 6 shows the results for the models in columns (5) and (6) of Table 5 under weighted estimation, focusing on our cultural indicators. Examination of the t-values shows that weighted estimation produces similar results and reinforces the positive role of aggregate Conformity and Tradition.

\subsection{Individual-Level Control Variables}

Table 7 shows the results of our control variables only, for the equation in column (6) of Table 5, as these results are very similar in all estimations. They are consistent with previous literature cited in this paper. Age, for example, displays the U-shaped relationship found

\footnotetext{
20 The between-country (sample size weighted) correlations for our cultural indicators based on national means show that Universalism has 0.93 correlation with Benevolence and 0.83 with Self-Direction. Security has 0.74 correlation with Tradition, while Power has 0.84 correlation with Achievement.
} 


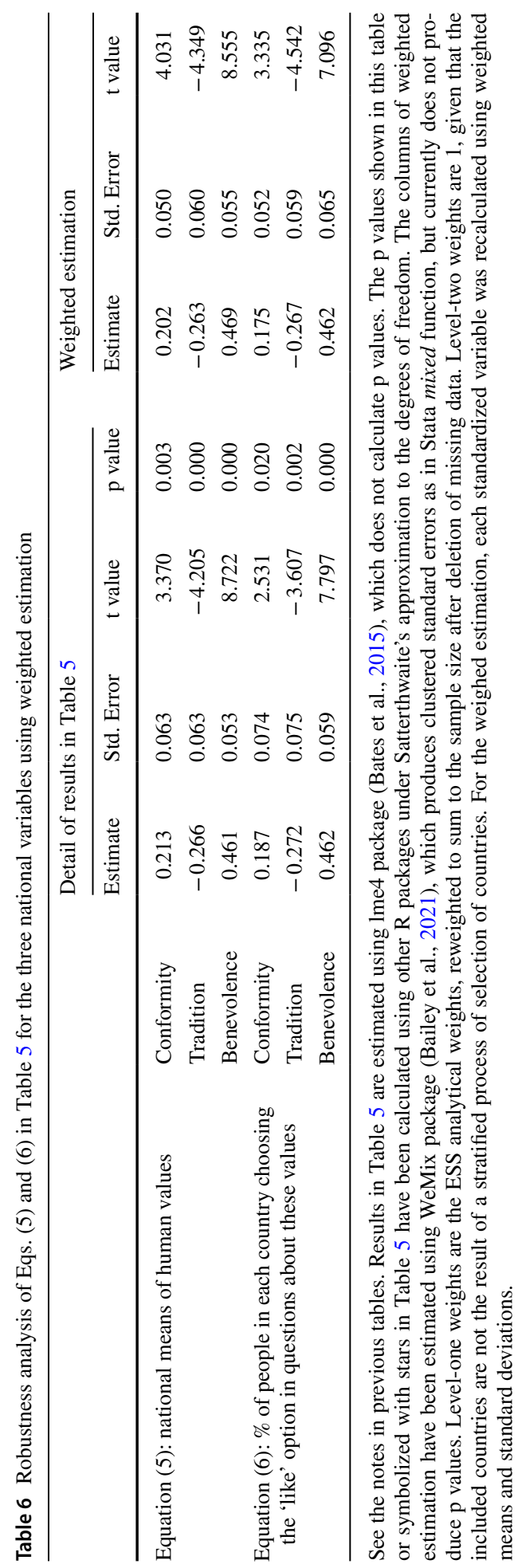


Table 7 Individual control variables $\left(X_{i k}\right)$ for Eq. (6) in Table 5

\begin{tabular}{ll}
\hline Age & $-1.19^{* * *}$ \\
Age squared & $1.27^{* * *}$ \\
Gender: Female & $0.05^{*}$ \\
Marital status: Married & $0.42^{* * *}$ \\
Marital status: Widowed or Never married & $0.12^{* *}$ \\
Tertiary education & $0.11^{\text {*** }}$ \\
Subjective health: Good & $1.71^{\text {*** }}$ \\
Subjective health: Fair & $1.01^{\text {*** }}$ \\
Living in a village or farm & $0.09^{* * *}$ \\
Political orientation: Centre & $0.17^{* * *}$ \\
Political orientation: Right & $0.42^{* * *}$ \\
Religiosity: Medium & $0.07^{\text {*** }}$ \\
Religiosity: High & $0.34^{* * *}$ \\
Trust in others: Medium & $0.32^{* * *}$ \\
Trust in others: High & $0.71^{* * *}$ \\
Income: Medium & $0.39^{* * *}$ \\
Income: High & $0.70^{* * *}$ \\
\hline
\end{tabular}

The reference category for Marital status is Legally separated or divorced; for Subjective health is Bad; for Political orientation is Left; for Religiosity, Trust in others and Income is Low. The original variable of Income is relative household's total net income, by decile. Original ESS variables have more categories, but these three-category versions produce similar empirical results. Likewise, for parsimony, the original categories of variables of education and domicile were reduced to dichotomous versions of the significant categories Tertiary education and Living in a village or farm. The reference category for Gender is Male. Age and $\mathrm{Age}^{2}$ are the only continuous variables and have been globally standardized

in other studies, meaning that the young and the old tend to report higher well-being. ${ }^{21}$ Our selection of indicators and parsimonious way of defining them also make minor contributions to well-being science.

\section{Conclusions}

This is the first paper to analyze the joint effects of human values on subjective well-being at individual and contextual levels. We use multilevel modelling to study the direct effects of cultural human values on Europeans' life satisfaction. We study these effects using two levels of geographical aggregation, two methods to aggregate the data from individuals to territories, and two scales of human values.

\footnotetext{
21 Aslam and Corrado (2012) capture the U-shaped association with dummy variables by age group. Ballas and Tramer (2012) and Neira et al. (2018) use age and age squared, although the size of their estimate for age squared is close to zero. The results that we are showing are obtained using scaled age and scaled age squared.
} 
One of our main results is that geographical scale matters when analyzing subjective well-being in European countries. Using the European Social Survey, we conclude that around $12 \%$ of the dispersion of life satisfaction is due to national factors, whereas only $2 \%$ is due to regional factors. Indeed, regional direct cultural effects are non-significant if national effects are considered in our models.

At individual level, we find that well-being is affected by the following human values, ordered by size of estimate: Hedonism (+), Benevolence (+), Achievement and Power (-), Tradition (-), and Conformity and Self-direction (+). This result is generally consistent with Sortheix and Schwartz's (2017) hypotheses on the effects of human values on wellbeing. The main difference is that we find a positive effect of individual Conformity, even though Conformity is a Conservation value, whose sign should be negative in Sortheix and Schwartz's (2017) theory.

Our main research question addresses the possible existence of happy cultures, or cultural attributes that promote the average individual's subjective well-being. We conclude that happy European cultures are those of countries with high levels of Benevolence and Conformity, and low levels of Tradition. When the Human Development Index is added to the model, Tradition ceases to be statistically significant, and the estimates of Benevolence and Conformity are lower. This finding is consistent with modernization theory. We are not studying cultural change, however, but the direct effects of cultural values on individuals' well-being, which are confirmed by our results.

Our research has several limitations. Firstly, our conclusions about the relative importance of regional and national factors are data dependent. As we analyzed regional effects using a mix of NUTS levels in a European sample, our results must be compared to those of other studies using different data. Secondly, despite the advantages of multilevel modelling for studying the direct effects of individual and aggregate human values, our results say nothing about causality among individual variables or among individual and aggregate variables. We indicate relevant statistical patterns to be considered in future research.

Neira et al. (2018) propose a research agenda for multilevel modelling as possible cuttingedge research in the science of well-being. Some of their proposals were to include contextual economic and cultural variables, and to perform different levels of geographical analysis. Our work makes contributions in these directions and can be continued in several ways. We have studied cultural human values, but these values only form part of other possible cultural attributes, such as beliefs or attitudes. Theoretical contributions from economics, sociology, and political science may suggest other contextual variables for consideration. Multilevel models with random slopes and cross-level interactions (mediations) are useful for researching why the same types of people may feel different in different cultures. The cause-effect relationship in happiness equations is not entirely clear (Ballas \& Tranmer, 2012) and should be further studied with longitudinal data. Further research is needed on the specific cultural dimension of Conformity: What distinguishing mechanisms are associated with Conformity and Tradition that affect subjective well-being in opposing directions? Can our results be confirmed using other data? Should Schwartz's approach to Conservation be reformulated?

Acknowledgements We wish to thank María Alló, Sandra Bermúdez, Malcolm Fairbrother, Teemu Makkonen, Isabel Neira, Mariano Rojas and Mikko Weckroth, for very useful discussions and comments. We are also grateful to two anonymous referees. We thank the helpful proofreading assistance of Anne Dewey. Usual disclaimers apply.

Funding Open Access funding provided thanks to the Universidade da Coruña/CISUG-CRUE-CSIC agreement with Springer Nature. 
Open Access This article is licensed under a Creative Commons Attribution 4.0 International License, which permits use, sharing, adaptation, distribution and reproduction in any medium or format, as long as you give appropriate credit to the original author(s) and the source, provide a link to the Creative Commons licence, and indicate if changes were made. The images or other third party material in this article are included in the article's Creative Commons licence, unless indicated otherwise in a credit line to the material. If material is not included in the article's Creative Commons licence and your intended use is not permitted by statutory regulation or exceeds the permitted use, you will need to obtain permission directly from the copyright holder. To view a copy of this licence, visit http://creativecommons.org/licenses/by/4.0/.

\section{References}

Andreoni, J., Nikiforakis, N., \& Siegenthaler, S. (2021). Predicting social tipping and norm change in controlled experiments. Proceedings of the National Academy of Sciences. https://doi.org/10.1073/pnas. 2014893118

Angrist, J. D., \& Pischke, J.-S. (2009). Mostly Harmless Econometrics: An Empiricist's Companion. Economics Books. Princeton University Press.

Aslam, A., \& Corrado, L. (2012). The geography of well-being. Journal of Economic Geography, 12(3), 627-649. https://doi.org/10.1093/jeg/lbr041

Bailey, P., Kelley, C., Nguyen, T., \& Huo, H. (2021). WeMix: Weighted mixed-effects models using multilevel pseudo maximum likelihood estimation. https:/CRAN.R-project.org/package=WeMix

Ballas, D., \& Tranmer, M. (2012). Happy people or happy places? A multilevel modeling approach to the analysis of happiness and well-being. International Regional Science Review, 35(1), 70-102. https:// doi.org/10.1177/0160017611403737

Bates, D., Mächler, M., Bolker, B., \& Walker, S. (2015). Fitting linear mixed-effects models using lme4. Journal of Statistical Software, 67(1), 1-48. https://doi.org/10.18637/jss.v067.i01

Bell, A., \& Jones, K. (2015). Explaining fixed effects: Random effects modeling of time-series cross-sectional and panel data. Political Science Research and Methods, 3(01), 133-153. https://doi.org/10. $1017 /$ psrm.2014.7

Bruna, F., \& Rungo, P. (2020). A note on the concavity of the happiness function in family support. Economics Bulletin, 40(2), 1122-1131.

Duncan, C., Jones, K., \& Moon, G. (1998). Context, composition and heterogeneity: Using multilevel models in health research. Social Science and Medicine, 46(1), 97-117. https://doi.org/10.1016/s02779536(97)00148-2

Elff, M., Heisig, J. P., Schaeffer, M., \& Shikano, S. (2021). Multilevel analysis with few clusters: Improving likelihood-based methods to provide unbiased estimates and accurate inference. British Journal of Political Science, 51(1), 412-426. https://doi.org/10.1017/S0007123419000097

Fairbrother, M., Johansson Sevä, I., \& Kulin, J. (2019). Political trust and the relationship between climate change beliefs and support for fossil fuel taxes: Evidence from a survey of 23 European countries. Global Environmental Change, 59, 102003. https://doi.org/10.1016/j.gloenvcha.2019.102003

Fischer, R., \& Poortinga, Y. H. (2012). Are cultural values the same as the values of individuals? An examination of similarities in personal, social and cultural value structures. International Journal of Cross Cultural Management, 12(2), 157-170. https://doi.org/10.1177/1470595812439867

Goodwin, J. L., Williams, A. L., \& Snell Herzog, P. (2020). Cross-cultural values: A meta-analysis of major quantitative studies in the last decade (2010-2020). Religions, 11(8), 396. https://doi.org/10.3390/rel11080396

Grosz, M. P., Schwartz, S., \& Lechner, C. (2021). The longitudinal interplay between personal values and subjective well-being. European Journal of Personality, 35(6), 881-897. https://doi.org/10.1177/ 08902070211012923.

Hitlin, S., \& Piliavin, J. A. (2004). Values: Reviving a dormant concept. Annual Review of Sociology, 30(1), 359-393. https://doi.org/10.1146/annurev.soc.30.012703.110640

Hofstede, G. (1980). Culture's Consequences: International Differences in Work-Related Values. SAGE Publications.

Huggins, R., \& Thompson, P. (2019). The behavioural foundations of urban and regional development: Culture, psychology and agency. Journal of Economic Geography, 19(1), 121-146.

Inglehart, R., \& Baker, W. E. (2000). Modernization, cultural change, and the persistence of traditional values. American Sociological Review, 65(1), 19-51. https://doi.org/10.2307/2657288

Inglehart, R., \& Klingemann, H.-D. (2000). Genes, culture, democracy, and happiness. Culture and subjective well-being (pp. 165-183). The MIT Press. 
Kaasa, A., Vadi, M., \& Varblane, U. (2013). European Social Survey as a source of new cultural dimensions estimates for regions. International Journal of Cross Cultural Management, 13(2), 137-157. https:// doi.org/10.1177/1470595813485379

Keyes, C. L. M. (1998). Social well-being. Social Psychology Quarterly, 61(2), 121-137. https://doi.org/10. 2307/2787065

Krys, K., Uchida, Y., Oishi, S., \& Diener, E. (2019). Open society fosters satisfaction: Explanation to why individualism associates with country level measures of satisfaction. The Journal of Positive Psychology, 14(6), 768-778. https://doi.org/10.1080/17439760.2018.1557243

Li, C., Zuckerman, M., \& Diener, E. (2021). Culture moderates the relation between gender inequality and well-being. Psychological Science, 32(6), 823-835. https://doi.org/10.1177/0956797620972492

Minkov, M., \& Hofstede, G. (2014). Clustering of 316 European regions on measures of values: Do Europe's countries have national cultures? Cross-Cultural Research, 48(2), 144-176. https://doi.org/ $10.1177 / 1069397113510866$

Minkov, M., Welzel, C., \& Schachner, M. (2020). Cultural evolution shifts the source of happiness from religion to subjective freedom. Journal of Happiness Studies, 21(8), 2873-2888.

Morrison, P. S., \& Weckroth, M. (2018). Human values, subjective well-being and the metropolitan region. Regional Studies, 52(3), 325-337. https://doi.org/10.1080/00343404.2017.1331036

Neira, I., Bruna, F., Portela, M., \& García-Aracil, A. (2018). Individual well-being, geographical heterogeneity and social capital. Journal of Happiness Studies, 19(4), 1067-1090. https://doi.org/10.1007/s10902-016-9840-Z

Pittau, M. G., Zelli, R., \& Gelman, A. (2010). Economic disparities and life satisfaction in European regions. Social Indicators Research, 96(2), 339-361. https://doi.org/10.1007/s11205-009-9481-2

Sagiv, L., \& Schwartz, S. H. (2000). Value priorities and subjective well-being: Direct relations and congruity effects. European Journal of Social Psychology, 30(2), 177-198. https://doi.org/10.1002/(SICI) 1099-0992(200003/04)30:2\%3c177::AID-EJSP982\%3e3.0.CO;2-Z

Sagiv, L., \& Schwartz, S. H. (2022). Personal Values Across Cultures. Annual Review of Psychology, 73.

Schwartz, S. H. (1992). Universals in the Content and Structure of Values: Theoretical Advances and Empirical Tests in 20 Countries. In M. P. Zanna (Ed.), Advances in Experimental Social Psychology (Vol. 25, pp. 1-65). Academic Press.

Schwartz, S. H., \& Sortheix, F. M. (2018). Values and Subjective Well-Being. In E. Diener, S. Oishi, \& L. Tay (Eds.), Handbook of well-being. Handbook of well-being: DEF Publishers.

Schyns, P. (1998). Crossnational differences in happiness: Economic and cultural factors explored. Social Indicators Research, 43(1), 3-26. https://doi.org/10.1023/A:1006814424293

Schyns, P. (2002). Wealth of nations, individual income and life satisfaction in 42 countries: A multilevel approach. Social Indicators Research, 60(1), 5-40. https://doi.org/10.1023/A:1021244511064

Snijders, T. A. B., \& Bosker, R. (2012). Multilevel Analysis: An Introduction to Basic and Advanced Multilevel Modeling (Second Edition.). Los Angeles, Calif.: SAGE Publications Ltd.

Solon, G., Haider, S. J., \& Wooldridge, J. M. (2015). What are we weighting for? Journal of Human Resources, 50(2), 301-316. https://doi.org/10.3368/jhr.50.2.301

Sortheix, F. M., \& Lönnqvist, J.-E. (2014). Personal value priorities and life satisfaction in Europe: The moderating role of socioeconomic development. Journal of Cross-Cultural Psychology, 45(2), 282299. https://doi.org/10.1177/0022022113504621

Sortheix, F. M., \& Schwartz, S. H. (2017). Values that underlie and undermine well-being: Variability across countries. European Journal of Personality, 31(2), 187-201. https://doi.org/10.1002/per.2096

Suh, E., Diener, E., Oishi, S., \& Triandis, H. C. (1998). The shifting basis of life satisfaction judgments across cultures: Emotions versus norms. Journal of Personality and Social Psychology, 74(2), 482. https://doi.org/10.1037/0022-3514.74.2.482

Tov, W., \& Diener, E. (2009). Culture and Subjective Well-Being. In Ed Diener (Ed.), Culture and WellBeing: The Collected Works of Ed Diener (pp. 9-41). Dordrecht: Springer Netherlands. https://doi.org/ 10.1007/978-90-481-2352-0_2

Veenhoven, R. (2015). Social conditions for human happiness: A review of research. International Journal of Psychology, 50(5), 379-391. https://doi.org/10.1002/ijop.12161

Weckroth, M., \& Kemppainen, T. (2016). Human capital, cultural values and economic performance in European regions. Regional Studies, Regional Science, 3(1), 239-257. https://doi.org/10.1080/21681376.2016.1177467

Welzel, C., \& Inglehart, R. (2010). Agency, values, and well-being: A human development model. Social Indicators Research, 97(1), 43-63.

Ye, D., Ng, Y.-K., \& Lian, Y. (2015). Culture and happiness. Social Indicators Research, 123(2), 519-547. https://doi.org/10.1007/s11205-014-0747-y

Publisher's Note Springer Nature remains neutral with regard to jurisdictional claims in published maps and institutional affiliations. 